\title{
Natural Occurrence of Secondary Bacterial Symbionts in Aphids from Tunisia, with a Focus on Genus Hyalopterus
}

\author{
Sana Zouari, ${ }^{1}$ Monia Kamel Ben Halima, ${ }^{1}$ Mariana Reyes-Prieto, ${ }^{2}$ Amparo Latorre, ${ }^{2,3}$ and \\ Rosario Gil ${ }^{2,4}$
}

1UR13AGR03: Cultures maraîchères conventionnelles et biologiques. Institut Supérieur Agronomique (ISA) de Chott Mariem, Université de Sousse Tunisie, ChottMariem, Tunisia, ${ }^{2}$ Institute for Integrative Systems Biology (I2SysBio), Universitatde València/CSIC, Paterna (Valencia) Spain, ${ }^{3}$ Área de Genómica y Salud, FISABIO - Salud Pública, València, Spain, and ${ }^{4}$ Corresponding author, e-mail: rosario.gil@uv.es

Subject Editor: Steve Perlman

Received 6 November 2017; Editorial decision 7 January 2018

\begin{abstract}
Aphids (Hemiptera: Aphididae) can harbor two types of bacterial symbionts. In addition to the obligate endosymbiont Buchnera aphidicola Munson, Baumann and Kinsey 1991 (Enterobacteriales: Enterobacteriaceae), several facultative symbiotic bacteria, called secondary (S) symbionts, have been identified among many important pest aphid species. To determine interpopulational diversity of S-symbionts, we carried out a survey in a total of 18 populations of six aphid species collected from six localities inTunisia, by performing a diagnostic polymerase chain reaction analysis of partial 16S-23S rRNA operon sequences. While $61.7 \%$ of individuals contained only Buchnera, three S-symbionts were found at different frequencies. Arsenophonus sp. Gherna et al. 1991 (Enterobacteriales: Enterobacteriaceae) was found in all species under study except for Acyrtosiphon pisum (Harris 1776) (Aphidinae: Macrosiphini); Serratia symbiotica Moran et al. 2005 (Enterobacteriales: Enterobacteriaceae) was present in all analyzed individuals of $A$. pisum but only sporadically in Aphis spiraecola (Patch 1914) (Aphidinae: Aphidini) and Hyalopterus amygdali (Blanchard 1840) (Aphidinae: Aphidini), while Hamiltonella defensa Moran et al. 2005 (Enterobacteriales: Enterobacteriaceae) was found in all analyzed individuals of one population of Aphis gossypii (Glover 1877) (Aphidinae: Aphidini) and sporadically in two populations of Hyalopterus. The lysogenic bacteriophage APSE-1 (A. pisum secondary endosymbiont, type 1 ) was detected in the three populations infected with $H$. defensa. This bacteriophage has been associated with moderate protection against braconid parasitoids in pea aphids. The high prevalence of Arsenophonus sp. in our samples is in accordance with previous studies indicating that, among gammaproteobacteria, this genus is one of the most widespread insect facultative symbionts.
\end{abstract}

Key words: Hyalopterus, parasitoid, secondary symbiont, Arsenophonus, Hamiltonella defensa, APSE

Aphids (Insecta: Hemiptera: Aphididae) maintain a well-characterized obligate mutualistic relationship with the gamma-proteobacterium Buchnera aphidicola (Munson et al. 1991). The bacterium lives within specialized aphid cells (bacteriocytes), it is maternally transmitted to the offspring and, like other bacteriocyte-associated endosymbionts, it provides to its host nutrients that are lacking in its unbalanced phloem diet, mainly essential amino acids and some vitamins (Baumann 2005). In addition to its obligate partner B. aphidicola, many aphids harbor additional facultative symbionts (Oliver et al. 2010). Although they are normally vertically transmitted from mother to progeny, these facultative symbionts can also undergo horizontal transmission, including transfer between host species (Sandström et al. 2001, Russell et al. 2003).

Aphid facultative symbionts are highly diverse. Among them, Serratia symbiotica and Regiella insecticola (Moran et al. 2005a) have only been found in aphids, while Hamiltonella defensa is also present in other sap-feeding insects such as psyllids and whiteflies
(Clark et al. 1992, Moran et al. 2005a, Rao et al. 2012). Some others, such as Arsenophonus Gherna et al. 1991 (Enterobacteriales: Enterobacteriaceae) (Gherna et al. 1991), Rickettsia da RochaLima, 1916 (Rickettsiales: Rickettsiaceae), and Spiroplasma Saglio, L'Hospital, Laflèche, Dupont, Bové, Tully and Freundt, 1973 (Entomoplasmatales: Spiroplasmataceae), are known to infect a wide variety of insects (Russell et al. 2003). These so-called secondary (S) symbionts are not essential for host survival, but their presence has been related with several positive effects on their hosts, mainly protection against certain environmental stresses, such as heat stress or natural enemies (Feldhaar 2011, Oliver et al. 2014). S-symbionts have not been found in all aphid species, nor in all populations of one species. However, at least in some cases, the lack of detection might be due to sampling problems. In addition to the pea aphid Acyrthosiphon pisum (Harris 1776) (Aphidinae: Macrosiphini), up to 156 species have been screened for particular 
facultative symbionts (Zytynska and Weisser 2016), mostly in a limited number of individuals, while only a few species from the subfamily Aphidinae have been extensively analyzed (mainly from genus Aphis Linnaeus 1758; e.g., Aphis fabae Scopoli 1763, Aphis gossypii Glover 1877, and Aphis craccivora Koch 1854).

Aphids must face the attack of numerous natural enemies, most notably hymenopteran parasitoids (Le Ralec et al. 2010), which are generally host specific. Many studies have shown that the infection of $H$. defensa strains provide defense to pea aphids against the parasitic wasp Aphidius ervi (Haliday 1834) (Hymenoptera: Braconidae: Aphidiinae) by killing the developing wasp larva or embryo in the aphid hemocoel (Oliver et al. 2003, 2005, 2006, 2009; Ferrari et al. 2004; Bensadia et al. 2006; Guay et al. 2009) and producing mummies (aphid remains containing developing parasitoids). In addition to the presence of protective symbionts, the resistance of A. pisum to the attack of $A$. ervi in natural populations has been linked to the aphid genetic background, the host plant, and temperature (Martinez et al. 2014a, McLean and Godfray 2015).

$H$. defensa has also been involved in the resistance of other aphid species to the attack of diverse aphidiine braconids, such as the protection of the black bean aphid, A. fabae, against Lysiphlebus fabarum (Marshall 1896) (Hymenoptera: Braconidae) (Vorburger et al. 2009, 2013; Schmid et al. 2012; Cayetano and Vorburger 2015), and of the cowpea aphid, A. craccivora, against Binodoxys communis (Gahan 1927) (Hymenoptera: Braconidae) (Desneux et al. 2009). In any case, the protection provided by $H$. defensa is not general toward all parasitoid species (Asplen et al. 2014; McLean et al. 2015; Martínez et al., 2016). Other aphid S-symbionts are also able to improve resistance to parasitoid wasps, albeit to a lesser extent. These include $R$. insecticola providing protection against Aphidius colemani (Hymenoptera: Braconidae) in Myzus persicae (Sulzer 1776) (Aphidinae, Macrosiphini) and A. fabae (Nyabuga et al. 2010, Vorburger et al. 2010), and coinfections of H. defensa-R. insecticola, $H$. defensa-S. symbiotica, $H$. defensa-Spiroplasma, and $R$. insecticola-Spiroplasma in A. pisum (Oliver et al. 2006, Nyabuga et al. 2010). The coinfection of $H$. defens $a$ and the facultative symbiont referred as PAXs (pea aphid X-type symbiont) was suggested to improve aphid resistance to parasitoids after exposure to heat stress conditions (Guay et al. 2009), although a recent study failed to corroborate this synergic effect (Doremus et al. 2017).

Besides the presumed influence of the aphid and parasitoid genotypes, the degree of protection provided by $H$. defensa is highly variable among bacterial strains (Martinez et al. 2014a,b, 2017; Rouchet and Vorburger 2012). Part of this variation must be due to the $H$. defensa chromosomal gene content, but it is also greatly influenced by the presence of a lysogenic lambda-like bacteriophage. Originally identified in strains from A. pisum, it was designated as 'A. pisum secondary endosymbiont' (APSE) phage (van der Wilk et al. 1999). Later on, APSE was found to be common not only in $H$. defensa strains of aphids but also in whiteflies and psyllids (Moran et al. 2005b; Degnan and Moran 2008a,b). Several APSE variants have been identified (Moran et al. 2005b, Degnan and Moran 2008a), each of them harboring a specific virulence cassette region, which encode homologs of toxins that are suspected to target embryonic wasp cells (Li et al. 2002, Nyabuga et al. 2010). The decrease of aphid mortality due to the attack of braconid parasitoids in aphids infected with $H$. defensa correlates to the presence of APSE, and it fluctuates among strains depending on the phage variant (Moran et al. 2005b, Oliver et al. 2005, Weldon et al. 2013). These variants might also be involved in the specificity against different parasitoid species (Degnan and Moran 2008a, Asplen et al. 2014). Strains lacking APSE (Degnan and Moran 2008a, Weldon et al. 2013), or with defective phages that carry inactivated toxin genes (Martinez et al. 2014b), provide no protection. APSE is not only present in H. defensa; Duron (2014) reported a wide variety of APSE phages in Arsenophonus, an S-symbiont exceptionally widespread in insects groups (including aphids, white flies, parasitoid wasps, triatomine bugs, louse flies, and bat flies; Nováková et al. 2009). However, the role of APSE in Arsenophonus symbioses remains to be characterized.

Aphids are considered a serious pest, causing great economic damages due to the direct removal of plant nutrients or the transmission of viruses causing plant diseases (Leclant 1996, Lozier et al. 2008a). The mealy aphids of the genus Hyalopterus (Koch 1854) (Hemiptera: Aphididae: Aphidinae) cause big damages in agricultural fields in Tunisia, where fruit trees represent $30 \%$ of agricultural production. They form colonies on the lower leaf surface, on twigs and even on branches, where they feed on phloem, causing premature leaf drop, retarded tree growth, and fewer and smaller fruits. Hyalopterus is a cosmopolitan genus, Mediterranean in origin, with only three recognized species Hyalopterus pruni (Geoffroy 1762), Hyalopterus amygdali (Blanchard 1840), and Hyalopterus arundiniformis (Ghulamullah 1941) (Aphidinae: Aphidini: Rhopalosiphina) (Lozier et al. 2007, Rakauskas et al. 2013, Favret et al. 2017). All three species are associated with common reed (Phragmites communis Cavanilles (Trinius) EX Steudel 1841, Poales: Poaceae) as summer host, and different Prunus species (Linnaeus 1753, Rosales: Rosaceae) as winter/spring hosts: H. amygdali is associated with almond trees (Prunus dulcis (Mill.) D. A. Webb), the second most abundant fruit tree in Tunisia $(194,740$ ha, $8.5 \%$ of the tree area); H. pruni is associated with plum trees (Prunus domestica Linnaeus) and blackthorn (Prunus spinosa Linnaeus); and H. arundiniformis with peach trees (Prunus persica (Linnaeus) Strokes 1812 NON Batsch 1801), distributed over 16.5 thousand hectares in Tunisia; all three species can also be found on apricot trees (Prunus armeniaca Linnaeus) (Blackman and Eastop 1994, 2000; Lozier et al. 2008a), which occupies 8.5 thousand hectares. Screening of Hyalopterus for facultative symbionts rendered negative results (Russell et al. 2003, Tsuchida et al. 2005) except in one study (Henry et al. 2015), where a few individuals were found to be infected by $H$. defensa .

Predators and parasitoids can be used for biological control of invasive aphids as an alternative to chemical pesticides. Because host and parasites coevolve (Rehman and Powell 2010), it is desirable to use natural enemies from the pest's region of origin in order to get the best possible biological control (Rosen 1986). Aphidius transcaspicus (Telenga 1958) (Hymenoptera: Braconidae: Aphidiinae) is a specific parasitoid of Hyalopterus from the Mediterranean, and has been selected to be used as a biological control agent against $H$. pruni (Latham and Mills 2012). Our laboratory has been studying this braconid for many years in order to use it as a biological control against the Hyalopterus pest in orchards. To do so, it is necessary to release high amounts of the wasp in the fields and, therefore, we need a way to mass rearing this parasitoid. The difficulties of rearing A. transcaspicus in aphids of the Hyalopterus complex under controlled conditions in greenhouse oriented us to try different aphid hosts. In addition to its natural host, at least in laboratory conditions, A. transcaspicus has been able to attack successfully several other aphid pests, such as A. pisum, Aphis spiraecola (Patch 1914) (unpublished data from our group [SZ]), A. fabae (Latham and Mills 2010), A. gossypii, A. craccivora, and M. persicae (Wang and Messing 2006), among others.

To select the best aphid host for mass rearing of A. transcaspicus, it is also important to determine the putative presence of protective symbionts in the available aphid populations (Vorburger 2018). As a starting point, and prior to making experimental determinations of susceptibility to parasitoids under controlled conditions, we have performed an analysis for the presence of S-symbionts in aphids from six different species collected in different locations in the North-Western 
and central-East of Tunisia, in the Golf of Hammamet and near the border with Algeria (Fig. 1; Table 1). This is the first time that the presence of S-symbionts has been determined in aphid populations from Tunisia.

\section{Materials and Methods}

\section{Aphid Collection}

Aphids of different species within subfamily Aphidinae were field collected from natural populations in different geographical locations of Tunisia in 2014, 2015, and 2016 (Table 1; Fig. 1). These include one species of the tribe Macrosiphini (A. pisum) and five species from the tribe Aphidinii, two of them from the genus Aphis (A. gosyypii and A. spireacola), plus all three known species from genus Hyalopterus (H. amygdali, H. arundiniformis, and H. pruni). No specific permissions were required for these collection activities and sampling did not involve endangered or protected species. In addition, aphid populations were established from viviparous individuals randomly collected in spring 2014, and reared in the laboratory under controlled conditions. The rearing was conducted on young shoots of common reed and almond for Hyalopterus species

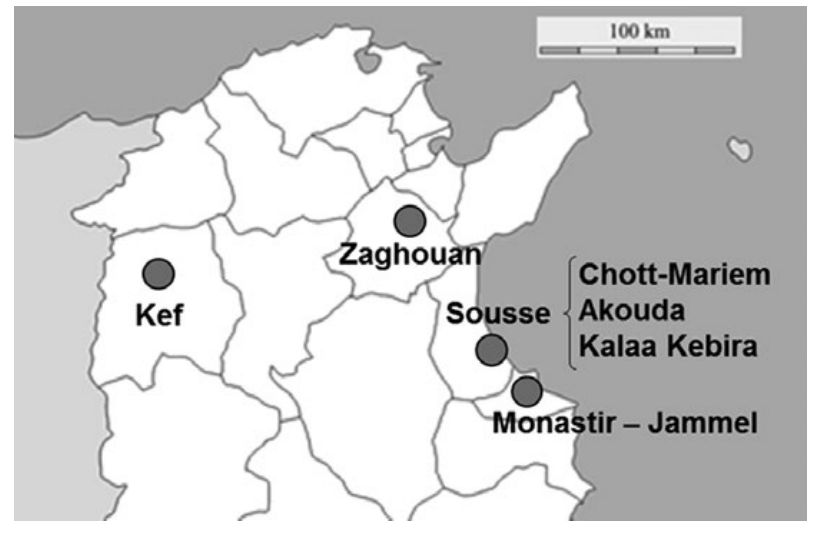

Fig. 1. Map of North Tunisia indicating the areas of aphids sampling. in Plexiglas's cages $(50 \times 50 \times 60 \mathrm{~cm}$ in size $)$ in glass greenhouses, as well as in warm rooms maintained at different temperatures, while A. pisum was reared on broad bean and pea at $25^{\circ} \mathrm{C}$ (Table 1), all of them with a relative humidity of $70 \%$.

\section{DNA Extraction}

Aphids were collected and stored in absolute ethanol until DNA extraction. Total DNA ( ${ }_{\mathrm{T}} \mathrm{DNA}$ ) of single individuals (or four aphids when indicated, see below) was obtained for all populations under study. Aphids were placed in a $1.5-\mathrm{ml}$ microtube, washed with phosphate-buffered saline (PBS) buffer ( $\mathrm{NaCl} 137 \mathrm{mM}, \mathrm{KCl} 2.7 \mathrm{mM}$, $\mathrm{Na}_{2} \mathrm{HPO}_{4} 10 \mathrm{mM}, \mathrm{KH}_{2} \mathrm{PO}_{4} 1.8 \mathrm{mM}$, pH 7.4), and crushed in $180 \mu \mathrm{l}$ of PBS buffer with a sterilized plastic pestle, using a pellet pestle cordless motor (Kimble Chase, Vineland, NJ). ${ }_{\mathrm{T}} \mathrm{DNA}$ was extracted using DNeasy Blood and Tissue Kit (QIAGEN, Hilden, Germany) following the manufacturer instructions.

\section{Diagnostic Screening for Secondary Symbionts and APSE}

The detection of the secondary bacteria was based on diagnostic polymerase chain reaction (PCR) analysis of partial 16S-23S rRNA operon sequences (Russell et al. 2003; Guay et al. 2009).

PCR amplifications were performed on insect ${ }_{T} \mathrm{DNA}$, with appropriate primer pairs (Table 2), using 50-60 $\mu$ mol of each primer/50 $\mu \mathrm{l}$ reaction, with KAPATaq DNA Polymerase Kit (Kapa Biosystems, Wilmington, MA). All PCR reactions included a negative control without template DNA. The thermal cycling profile was as follows: an initial denaturation step at $94^{\circ} \mathrm{C}$ for $4 \mathrm{~min}$, followed by 40 cycles of $94^{\circ} \mathrm{C}$ for $50 \mathrm{~s}$, the appropriate annealing temperature (see Table 2) for $1 \mathrm{~min}$, and $72^{\circ} \mathrm{C}$ for $1.5 \mathrm{~min}$, plus a final extension step of $7 \mathrm{~min}$ at $72^{\circ} \mathrm{C}$. PCR products were run on $1 \%$ agarose gels with ethidium bromide and visualized with UV light.

As a positive control of ${ }_{\mathrm{T}} \mathrm{DNA}$ quality, a first PCR reaction (control PCR, C) was performed using universal direct and reverse primers to amplify a fragment of the $16 \mathrm{~S}$ rRNA gene, which also amplifies B. aphidicola. Aphid DNA samples where Buchnera could not be

Table 1. Insect samples analyzed in this study

\begin{tabular}{|c|c|c|c|c|}
\hline Population ID & Aphid & Host plant & Origin & Collection time \\
\hline \multirow[t]{2}{*}{ Ap-1 } & \multirow[t]{2}{*}{ Acyrthosiphon pisum } & Broad bean & Chott-Mariem $^{a}\left(25^{\circ} \mathrm{C}\right)$ & May 2015 \\
\hline & & Pea & Chott-Mariem $^{a}\left(25^{\circ} \mathrm{C}\right)$ & May 2015 \\
\hline $\mathrm{Ag}-1$ & Aphis gossypii & Chinese hibiscus & Chott-Mariem & May 2015 \\
\hline $\mathrm{Ag}-2$ & A. gossypii & Muskmelon & Chott-Mariem & May 2015 \\
\hline As-1 & A. spiraecola & Plum & Kalaa Kebira & May 2015 \\
\hline Ha-1 & Hyalopterus amygdali & Common reed & $\begin{array}{l}\text { Chott-Mariem }^{a}(25,28,30 \text {, and } \\
\left.\quad 35^{\circ} \mathrm{C}\right)\end{array}$ & May 2015 \\
\hline $\mathrm{Ha}-2$ & H. amygdali & Almond & Akouda $^{a}\left(15,20,25\right.$, and $\left.35^{\circ} \mathrm{C}\right)$ & June 2015 \\
\hline $\mathrm{Ha}-3$ & H. amygdali & Almond & Chott-Mariem & December 2015 \\
\hline $\mathrm{Ha}-4$ & H. amygdali & Almond & Jammel & May 2015, May 2016 \\
\hline $\mathrm{Ha}-5$ & H. amygdali & Almond & Kef & June 2014, April 2016 \\
\hline На-6 & H. amygdali & Almond & Zaghouan & May 2016 \\
\hline $\mathrm{Ha}-7$ & H. amygdali & Almond & Akouda & December 2015 \\
\hline Har-1 & Hyalopterus arundiniformis & Peach & Chott-Mariem & March 2016 \\
\hline Har-2 & H. arundiniformis & Peach & Jammel & April 2016 \\
\hline Har-3 & H. arundiniformis & Peach & Kef & April 2016 \\
\hline Har-4 & H. arundiniformis & Apricot & Akouda & December 2015, April 2016 \\
\hline Hpr-1 & Hyalopterus pruni & Apricot & Kef & June 2014, April 2016 \\
\hline Hpr-2 & H. pruni & Blackthorn & Kef & June 2014, May 2016 \\
\hline Hpr-3 & H. pruni & Plum & Kef & April 2016 \\
\hline
\end{tabular}

${ }^{a}$ Natural origin of populations maintained in greenhouse at the temperatures indicated in brackets. 
confirmed must be considered unreliable and were discarded for further analysis. Next, for the detection of S-symbionts (Diagnostic PCR 1, DP1), we used a universal direct primer targeting the 16S rRNA gene, and a universal reverse primer targeting the $23 \mathrm{~S}$ rRNA gene.

According to the experimental protocol of Sandström et al. (2001), the amplicons obtained from the first quality PCR test and DP1 were digested with the restriction enzymes ClaI, SacI, SalI, and $\mathrm{XbaI}$, and the digestions were run in $1 \%$ agarose gels to further confirm infection status. The results were indicative of the presence of one (B. aphidicola) or more than one bacterial species in the sample. This was an important step in order to discard false-negative results for the presence of S-symbionts during the following steps. All positive samples were PCR amplified using primers for the 16S-23S operon, which are able to amplify only $S$-symbionts because the two genes are separated in B. aphidicola (DP1; Table 2). If no amplicon was obtained in this analysis, all the procedures were repeated but including four aphids in a single DNA extraction. When the results remained negative, the sample was considered to be free of S-symbionts. Positive ${ }_{\mathrm{T}} \mathrm{DNA}$ samples for S-symbionts were tested for the presence of APSE phages using specific primers (Table 2) to amplify a fragment of the gene P45, encoding the phage DNA polymerase.

For the specific detection of each suspected S-symbiont (Diagnostic PCR 2, DP2), we used a specific forward primer for each symbiont and a universal reverse primer (Table 2). When needed, amplicons with the expected size were excised from the gel prior to sequencing. If more than one S-symbiont was suspected, purified amplicons were cloned using pGEM-T Easy Vector System I Kit (Promega). At least 10 individual clones were analyzed by direct colony PCR, using T7 and SP6 universal primers to amplify the inserts.

\section{DNA Sequencing and Phylogenetic Analysis}

ABI sequencing was performed on successfully amplified products from the DP1, DP2, and APSE analyses at the SCSIE sequencing facility of the Universitat de València. Sequencing reads were quality surveyed and assembled with the Staden Package (http:// staden.sourceforge.net/; Staden et al. 2000). Sequences were then compared with those in the GenBank nucleotide sequence database using BLAST searches (http://blast.ncbi.nlm.nih.gov/ Blast.cgi), to confirm the identity of the detected symbiont. The DNA sequences determined in this study have been deposited in GenBank with the following accession numbers: Arsenophonus sp., MG257468-MG257478; Erwinia sp., MG257479; H. defensa, MG257480-MG257482; S. symbiotica, MG257483-MG257485; and APSE: MG257486.

APSE sequences available in GenBank were used to perform a sequence alignment with MAFFT v7.037b software (Katoh and Standley 2013; Table 3). Uninformative positions were located and

Table 2. Primers used in this study

\begin{tabular}{|c|c|c|c|c|c|c|}
\hline Target & Primer name & Primer sequence $\left(5^{\prime}-3^{\prime}\right)$ & Gene & Use & $T_{\mathrm{m}}\left({ }^{\circ} \mathrm{C}\right)$ & Reference \\
\hline Bacteria & $1502 \mathrm{R}$ & GTTACGACTTCACCCCAG & $16 \mathrm{~S}$ rRNA & $\mathrm{C}, \mathrm{S}$ & 52 & Russell et al. 2003 \\
\hline Bacteria & $10 \mathrm{~F}$ & AGTTTGATCATGGCTCAGATTG & $16 \mathrm{~S}$ rRNA & $\mathrm{C}, \mathrm{DP} 1, \mathrm{~S}$ & 52 & Sandström et al. 2001 \\
\hline S- symbiont & $480 \mathrm{R}$ & CACGGTACTGGTTCACTATCGGTC & $23 \mathrm{~S}$ rRNA & DP1 & 52 & Sandström et al. 2001 \\
\hline Arsenophonus & Ars16SR & TTAGCTCCGGAGGCCACAGT & $16 \mathrm{~S}$ rRNA & $\mathrm{DP} 2, \mathrm{~S}$ & 51 & Tsuchida et al. 2002 \\
\hline Hamiltonella defensa & PABSF & AGCGCAGTTTACTGAGTTCA & $16 \mathrm{~S}$ rRNA & $\mathrm{DP} 2, \mathrm{~S}$ & 55 & Darby et al. 2001 \\
\hline PAXS & PAXSF & GAAGCAATGCAAAGAGTGTTGC & $16 \mathrm{~S}$ rRNA & DP2 & 55 & Guay et al. 2009 \\
\hline Regiella insecticola & U99F & ATCGGGGAGTAGCTTGCTAC & $16 \mathrm{~S}$ rRNA & DP2 & 56 & Sandström et al. 2001 \\
\hline Serratia symbiotica & PASScmp & GCAATGTCTTATTAACACAT & $16 \mathrm{~S}$ rRNA & $\mathrm{DP} 2, \mathrm{~S}$ & 55 & Fukatsu et al. 2000 \\
\hline APSE & APSE30.1F & ACGGCACTTAAACGCTATCC & P45 & $\mathrm{P}, \mathrm{S}$ & 53 & Taylor et al. 2011 \\
\hline APSE & APSE31.1R & TGGGATGTGTATGGACGTTG & P45 & $\mathrm{P}, \mathrm{S}$ & 53 & $\begin{array}{l}\text { Degnan and Moran } \\
2008 \mathrm{a}\end{array}$ \\
\hline
\end{tabular}

C, control PCR reaction; DP1, diagnostic PCR for the presence of S-symbionts; DP2, diagnostic PCR for the presence of a specific S-symbiont; P, phage detection; S, sequencing.

Table 3. APSE sequences included in the phylogenetic analysis

\begin{tabular}{|c|c|c|c|}
\hline Accession number & Bacteria & Insect host & Reference \\
\hline HM594699.1 & Arsenophonus sp. & Trialeurodes vaporariorum & Taylor et al. (2011) \\
\hline HM594700.1 & Arsenophonus nasoniae & Spalangia cameroni & Taylor et al. (2011) \\
\hline HM594701.1 & A. nasoniae & Eupelmus vesicularis & Taylor et al. (2011) \\
\hline HM594702.1 & A. nasoniae & Nasonia vitripennis & Taylor et al. (2011) \\
\hline AF157835.1 & Hamiltonella defensa & Acyrtosiphon pisum & Van der Wilk et al. (1999) \\
\hline EU021718.1 & H. defensa T5A & A. pisum & Degnan and Moran (2008b) \\
\hline EU021719.1 & H. defensa A1A & A. pisum & Degnan and Moran (2008b) \\
\hline EU021722.1 & H. defensa 5ATac & A. pisum & Degnan and Moran (2008b) \\
\hline EU021991.1 & H. defensa A2F & A. pisum & Degnan and Moran (2008b) \\
\hline EU021996.1 & H. defensa N4 & Chaitophorus sp. & Degnan and Moran (2008b) \\
\hline EU794057.1 & H. defensa A1A & A. pisum & Degnan and Moran (2008b) \\
\hline KT028654.1 & H. defensa & A. pisum (clone Medicago_217) & McLean and Godfray (2015) \\
\hline KT028655.1 & H. defensa & A. pisum (clone Medicago_308) & McLean and Godfray (2015) \\
\hline KT028670.1 & H. defensa & A. pisum (clone Ononis_257) & McLean and Godfray (2015) \\
\hline KT028671.1 & H. defensa & A. pisum (clone Ononis_256) & McLean and Godfray (2015) \\
\hline MG257486 & H. defensa & Aphis gossypii, H. amigdaly, Hyalopterus pruni & This study \\
\hline EU039462.1 & S-symbiont & Glycaspis brimblecombei & Hansen et al. (2007) \\
\hline
\end{tabular}


masked with GBLOCKS 0.91b (Castresana 2000). ClustalX (Larkin et al. 2007) was used to change the file format from fasta to nexus, and the obtained nexus file was manually edited to add MrBayes parameters. Finally, a phylogenetic analysis was performed using Bayesian Inference with MrBayes v3.2.5 software (Ronquist et al. 2012). Nodal support was estimated by posterior probabilities using the sumt command in MrBayes. We used FigTree v1.4.0 software (http://tree.bio.ed.ac.uk/software/figtree/) to visualize and edit the phylogenetic tree.

\section{Results and Discussion}

A. transcaspicus is a specific and indigenous parasitoid of the Mediterranean region that has co-evolved with its hosts, aphids from genus Hyalopterus (Lozier et al. 2008b, Latham and Mills 2012), and it has been selected to be used as a biological control agent against these aphids. However, because Hyalopterus's host plants are trees belonging to Prunus genus and reeds, it is time consuming and expensive to rear big amounts of A. transcaspicus on Hyalopterus spp. under controlled conditions. In laboratory conditions, and even in the open field, A. transcaspicus can also attack other aphid species (Wang and Messing 2006; Latham and Mills 2010). While trying to find an alternative host for mass rearing of A. transcaspicus, we noticed different mummification $(<7 \%)$ and emergence rates $(<20 \%)$ among several species, including A. pisum, A. fabae, A. gossypii, and A. spiraecola (unpublished data from our group [SZ]). This phenomenon might be caused by the presence of S-symbionts with a protective role against the attack of parasitoids, as described in other aphids. However, there is only scarce information about the presence of S-symbionts in Hyalopterus spp., and only a few studies included samples from Africa or Mediterranean coastal regions (Zytynska and Weisser 2016). For this reason, we decided to determine the presence of putatively protective symbionts in Hyalopterus spp. and potential alternative hosts, reared in our greenhouse and from different natural populations of the northwestern and central-east of Tunisia (Fig. 1; Table 1).

We screened a total of 194 aphids from six different species. In a first step, ${ }_{T}$ DNA was obtained from single individuals and all samples were analyzed by PCR using universal primers for the $16 \mathrm{~S}$ rRNA gene (Table 2), in order to test for DNA quality. Because B. aphidicola must always be present, only the 162 positive samples were further analyzed. Second, the obtained amplicons were digested with four different restriction enzymes that gave a known pattern for B. aphidicola and the three most common S-symbionts, S. symbiotica, H. defensa, and R. insecticola (Sandström et al. 2001). All samples that gave positive results were also PCR-amplified using primers that were able to amplify only S-symbionts (DP1; Table 2). Next, samples that gave positive DP1 results were further analyzed with species-specific primers (DP2; Table 2). Finally, the obtained DP2 amplicons were sequenced. For those samples that were positive in the DP1 analysis but did not give any DP2 amplicon, the product of DP1 was sequenced instead, allowing the detection of bacteria for which no species-specific primers were designed. All obtained sequences were analyzed by BLAST, to confirm the identity of the detected symbiont. The sequencing step revealed that the Arsenophonus-specific primers gave some unspecific amplification of samples that contained Hamiltonella. The final results are summarized in Table 4.

Nearly all screenings for the presence of S-symbiont across insects have used diagnostic PCR to determine the presence of particular bacterial species (Oliver et al. 2014). In fact, Henry et al. (2015) showed that species-specific primers are very reliable in detecting S-symbionts in aphids because the use of NGS technologies gave almost the same results. Therefore, even though the number of aphids analyzed is limited and we cannot discard false-negative results, our results indicate a relatively high incidence of S-symbionts in the analyzed populations.

The most frequently found facultative symbiont was Arsenophonus spp. In fact, except for A. pisum, we found it in all

Table 4. S-symbionts identified in the aphid populations analyzed

\begin{tabular}{|c|c|c|c|c|c|}
\hline Population ID & $\begin{array}{l}\text { Number of indi- } \\
\text { viduals analyzed }\end{array}$ & Arsenophonus sp. & Serratia symbiotica & Hamiltonella defens $a^{a}$ & Erwinia sp. \\
\hline Ap-1 (bean) & 4 & & 4 & & \\
\hline Ap-1 (pea) & 4 & & 4 & & \\
\hline Ag-1 & 5 & & & 5 & \\
\hline $\mathrm{Ag}-2$ & 11 & 11 & & & \\
\hline As-1 & 7 & 3 & $1^{b}$ & & \\
\hline Ha-1 (natural) & 9 & 3 & 1 & 1 & \\
\hline Ha-1 (greenhouse) & 25 & 11 & $2^{c}$ & & \\
\hline $\mathrm{Ha}-2$ & 17 & & & & \\
\hline $\mathrm{Ha}-3$ & 5 & & & & \\
\hline $\mathrm{Ha}-4$ & 12 & 4 & & & \\
\hline Ha-5 & 10 & 1 & & & \\
\hline Ha-6 & 4 & & & & \\
\hline На-7 & 4 & 1 & & & \\
\hline Har-1 & 4 & 1 & & & \\
\hline Har-2 & 4 & 3 & & & \\
\hline Har-3 & 4 & 1 & & & \\
\hline Har-4 & 10 & 5 & & & \\
\hline Hpr-1 & 4 & 1 & & & \\
\hline Hpr-2 & 8 & & & 1 & 1 \\
\hline Hpr-3 & 11 & & & & \\
\hline
\end{tabular}

\footnotetext{
${ }^{a}$ All samples positive for Hamiltonella were also positive for APSE-1.

${ }^{b}$ The same individual gave a positive result for Arsenophonus and Serratia.

$\ddagger^{c}$ One individual positive for Serratia was also positive for Arsenophonus.
} 
species under study, although not in all populations and, in many cases, it was the only S-symbiont detected. This is the first statement of the presence of Arsenophonus in the genus Hyalopterus. Enterobacteriaceae of genus Arsenophonus have been increasingly discovered as facultative symbionts in insects belonging to multiple taxa, and it has been estimated to infect almost $5 \%$ of arthropods (Nováková et al. 2009). This genus presents a high ecological versatility, with switches between entirely different life styles, from male-killers (e.g. Arsenophonus nasoniae Gherna et al. 1991 (Enterobacteriales: Enterobacteriaceae) infecting the parasitic wasp Nasonia vitripennis Walker 1836, Hymenoptera: Pteromalinae; Taylor et al. 2011) to beneficial symbiont, as it seems to be the case of the soybean aphid, Aphis glycines (Matsumara, Aphidinae: Aphidinii) (Wulff and White 2015). Nevertheless, despite being found in $7 \%$ of all aphid species, and $30 \%$ of species within the genus Aphis (Jousselin et al. 2013), the function of this bacterium is unknown in most aphids.

Hamiltonella was sporadically found only in three populations analyzed in this work, each one belonging to a different species. We detected it in all individuals analyzed from a natural population of A. gossypii feeding on Chinese hibiscus, but not on a second natural population of the same aphid species feeding on melon. It was also found in a single individual in one natural population of $H$. pruni feeding on apricot, and in another single individual of
H. amygdali feeding on the summer host plant common reed, but not in any of the analyzed aphids from colonies established in a greenhouse derived from the later natural population (Table 4). Previous studies on the presence of $H$. defensa in pea aphids indicate that this S-symbiont appears sporadically in A. pisum populations, and it is beneficial only when parasitoids are present (Oliver et al. 2008). Therefore, infection frequencies decrease in the absence of parasitoids.

Because the protective effect of Hamiltonella has been related with the presence of the APSE prophage, we screened for the incidence of APSE infections using a PCR assay based on the P45 gene, involved in phage DNA synthesis (Degnan and Moran 2008b). The analysis revealed that all samples that gave positive results for Hamiltonella also possessed APSE, and that the obtained amplicon was identical in all of them. The subsequent phylogenetic analysis suggests that it belongs to the APSE-1 clade (Fig. 2). In previous studies performed on A. pisum, this strain has been associated with moderate-to-strong protection against $A$. ervi (Degnan and Moran 2008a, Oliver et al. 2009, Weldon et al. 2013, McLean 2015). APSE has also been frequently detected in Arsenophonus spp. (Duron 2014). For this reason, the same screening analysis was also performed for all samples that gave positive results for other S-symbionts, but all of them gave negative results for the presence of the prophage.

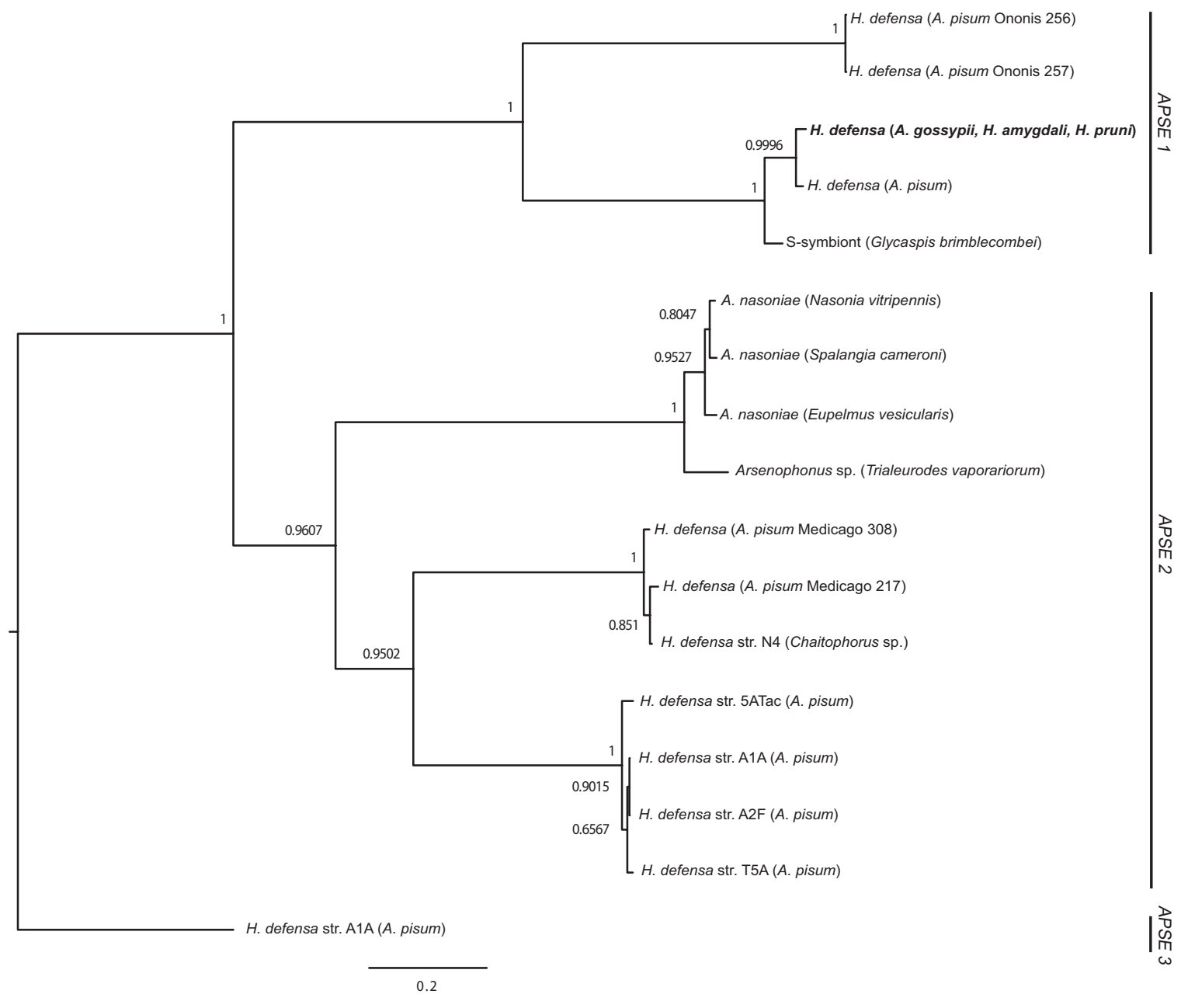

Fig. 2. Phylogenetic analysis of the APSE-P45 gene partial nucleotide sequences obtained from the different populations analyzed (in bold). Bayesian posterior probabilities are indicated as nodal support. Scale bar represents substitutions per site. 
S. symbiotica was found in three of the aphid species analyzed. It was present in all analyzed individuals from the A. pisum populations maintained in our greenhouse in Chott-Mariem, reared on peas and beans, established from a natural population in 2014. This is not an unexpected result because $S$. symbiotica has been frequently associated with pea aphids, being more abundant in warm conditions (Montllor et al. 2002). S. symbiotica in pea aphids has also been suggested to provide mild protection against parasitism by A. ervi (Oliver et al. 2003), although in that case no direct fitness benefit was observed (Oliver et al. 2008). In fact, because there is limited evidence for known defensive factors in the S. symbiotica genome (Burke and Moran 2011), the above observations might be related to other benefits, such as thermal tolerance (Montllor et al. 2002, Russell and Moran 2006).

Among the different species of tribe Aphidini analyzed, S. symbiotica was only sporadically detected in one population of $H$. amygdali from Chott-Mariem. The S-symbiont was detected in one individual collected on spring 2015 from a natural population feeding on common reed, and also in two aphids from a population established from the original one and reared in a greenhouse at $28^{\circ} \mathrm{C}$. However, it was not found in aphids from the same population reared at lower or higher temperatures $\left(25,30\right.$, and $\left.35^{\circ} \mathrm{C}\right)$. The same natural population of $H$. amygdali gave also one positive result for the presence of $H$. defensa, although not simultaneously with $S$. symbiotica. It is unusual to find such small incidence of Serratia infections in aphids from a warm area. It might indicate that the increased thermal tolerance attributed to this bacterium is not a general trait for different aphid species.

Besides the common aphid heritable S-symbionts, the sequencing analysis of the amplicon obtained in the DP1 analysis of one H. pruni aphid captured on blackthorn allowed the identification of Erwinia spp. Winslow et al., 1920 (Enterobacteriales: Enterobacteriaceae), a plant pathogen that several studies have detected as a gut associate in some aphids (reviewed in Gauthier et al. 2015). Its presence in the sampled aphids might just reflect their acquisition form the host plant during feeding. Although two species of this genus, E. aphidicola and E. iniecta, have been described to negatively affect the infected aphid (Harada et al. 1997, Campillo et al. 2015), it is not clear whether Erwinia acts as an aphid pathogen, commensal, mutualist, it uses aphids as alternative hosts to plants, or it is just acquired during aphid feeding, so that the aphid acts as a vector for the plant pathogen.

\section{Concluding Remarks}

Recently, Zytynska and Weisser (2016) performed a comprehensive search of all available information about the presence of aphids $\mathrm{S}$-symbionts, to highlight the geographical areas that should be explored in order to have a better understanding of the global distributions of these facultative bacteria. At the continental scale, Africa is one of the less explored world areas regarding this subject, with only a few studies performed on a limited number of aphid species. Therefore, even though the number of aphids analyzed in this work is limited, this is the first survey on the presence of S-symbionts in Tunisian aphids causing important damage in crops. Our results indicate that S-symbionts, mainly Arsenophonus spp., are widely present in the analyzed populations. Further studies need to be conducted in order to determine whether their presence has ecologically important benefits and the impact of temperature and plant hosts in such benefits. In any case, the presence of Hamiltonella is sporadic in the analyzed populations, although all strains detected present APSE. To select for a good candidate for massive rearing of A. transcaspicus, it would be interesting to previously screen for the presence of APSE, and select one APSEfree population.

\section{Acknowledgments}

This work was supported by grants BFU2015-64322-C2-1-R (co-financed by FEDER funds and Ministerio de Economía y Competitividad, Spain), PrometeoII/2014/065 (Conselleria d'Educació, Generalitat Valenciana, Spain). S. Zouari is a recipient of a fellowship from Tunisian Ministry of Higher Education, and a grant from the Tunisian-Algerian project 1521ICH/RO, 2012 (co-financed by Tunisian and Algerian Ministries of Higher Education). M. Reyes-Prieto is a recipient of a fellowship (number 538243) from Consejo Nacional de Ciencia y Tecnologia, México.

\section{References Cited}

Asplen, M. K., N. Bano, C. M. Brady, N. Desneux, K. R. Hopper, C. Malouines, K. M. Oliver, J. A. White, and G. E. Heimpel. 2014. Specialisation of bacterial endosymbionts that protect aphids from parasitoids. Ecol. Entomol. 39: 736-739.

Baumann, P. 2005. Biology bacteriocyte-associated endosymbionts of plant sap-sucking insects. Annu. Rev. Microbiol. 59: 155-189.

Bensadia, F., S. Boudreault, J. F. Guay, D. Michaud, and C. Cloutier. 2006. Aphid clonal resistance to a parasitoid fails under heat stress. J. Insect Physiol. 52: 146-157.

Blackman, R. L., and V. F. Eastop. 1994. Aphids on the world's trees: an identification and information guide. CABI, Wallingford, England, pp. 362-370.

Blackman, R. L., and V. F. Eastop. 2000. Aphids on the world's crops: an identification and information guide. John Wiley and Sons, Chichester, England, pp. 279-280.

Burke, G. R., and N. A. Moran. 2011. Massive genomic decay in Serratia symbiotica, a recently evolved symbiont of aphids. Genome Biol. Evol. 3: 195-208.

Campillo, T., E. Luna, P. Portier, M. Fischer-Le Saux, N. Lapitan, N. A. Tisserat, and J. E. Leach. 2015. Erwinia iniecta sp. nov., isolated from Russian wheat aphid (Diuraphis noxia). Int. J. Syst. Evol. Microbiol. 65: 3625-3633.

Castresana, J. 2000. Selection of conserved blocks from multiple alignments for their use in phylogenetic analysis. Mol. Biol. Evol. 17: 540-552.

Cayetano, L., and C. Vorburger. 2015. Symbiont-conferred protection against Hymenopteran parasitoids in aphids: how general is it? Ecol. Entomol. 40: 85-93.

Clark, M. A., L. Baumann, M. A. Munson, P. Baumann, B. C. Campbell, J. E. Duffus, L. S. Osborne, and N. A. Moran. 1992. The eubacterial endosymbionts of whiteflies (Homoptera: Aleyrodoidea) constitute a lineage distinct from the endosymbionts of aphids and mealybugs. Curr. Microbiol. 25: 119-123.

Darby, A. C., L. M. Birkle, S. L. Turner, and A. E. Douglas. 2001. An aphidborne bacterium allied to the secondary symbionts of whitefly. FEMS Microbiol. Ecol. 36: 43-50.

Degnan, P. H., and N. A. Moran. 2008a. Diverse phage-encoded toxins in a protective insect endosymbiont. Appl. Environ. Microbiol. 74: 6782-6791.

Degnan, P. H., and N. A. Moran. 2008b. Evolutionary genetics of a defensive facultative symbiont of insects: exchange of toxin-encoding bacteriophage. Mol. Ecol. 17: 916-929.

Desneux, N., R. J. Barta, K. A. Hoelmer, K. R. Hopper, and G. E. Heimpel. 2009. Multifaceted determinants of host specificity in an aphid parasitoid. Oecologia. 160: 387-398.

Doremus, M. R., A. H. Smith, K. L. Kim, A. J. Holder, J. A. Russell, and K. M. Oliver. 2017. Breakdown of a defensive symbiosis, but not endogenous defences, at elevated temperatures. Mol. Ecol. 00: 1-14.

Duron, O. 2014. Arsenophonus insect symbionts are commonly infected with APSE, a bacteriophage involved in protective symbiosis. fems Microbiol. Ecol. 90: 184-194. 
Favret, C., N. Meshram, G. Miller, J. M. Nieto Nafria, and A. Stekolshchikov. 2017. A synonymic revision of the Prunus-infesting aphid genus Hyalopterus Koch 1854 (Hemiptera: Aphididae). P. Entomol. Soc. Wash. 119: 565-574.

Feldhaar, H. 2011. Bacterial symbionts as mediators of ecologically important traits of insect hosts. Ecol. Entomol. 36: 533-543.

Ferrari, J., A. C. Darby, H. C. J. G. Daniell, and A. E. Douglas. 2004. Linking the bacterial community in pea aphids with host-plant use and natural enemy resistance. Ecol. Entomol. 29: 60-65.

Fukatsu, T., N. Nikoh, R. Kawai, and R. Koga. 2000. The secondary endosymbiotic bacterium of the pea aphid Acyrthosiphon pisum (Insecta: Homoptera). Appl. Environ. Microbiol. 66: 2748-2758.

Gauthier, J. P., Y. Outreman, L. Mieuzet, and J. C. Simon. 2015. Bacterial communities associated with host-adapted populations of pea aphids revealed by deep sequencing of $16 \mathrm{~S}$ ribosomal DNA. PLoS One. 10: e0120664.

Gherna, R. L., J. H. Werren, W. Weisburg, R. Cote, C. R. Woese, L. Mandelco, and D. J. Brenner. 1991. Arsenophonus nasoniae gen. nov., sp. nov., the causative agent of the son-killer trait in the parasitic wasp Nasonia vitripennis. Int. J. Syst. Bacteriol. 41: 563-565.

Guay, J. F., S. Boudreault, D. Michaud, and C. Cloutier. 2009. Impact of environmental stress on aphid clonal resistance to parasitoids: role of Hamiltonella defensa bacterial symbiosis in association with a new facultative symbiont of the pea aphid. J. Insect Physiol. 55: 919-926.

Hansen, A. K., G. Jeong, T. D. Paine, and R. Stouthamer. 2007. Frequency of secondary symbiont infection in an invasive psyllid relates to parasitism pressure on a geographic scale in California. Appl. Environ. Microbiol. 73: 7531-7535.

Harada, H., H. Oyaizu, Y. Kosako, and H. Ishikawa. 1997. Erwinia aphidicola, a new species isolated from pea aphid, Acyrthosiphon pisum. J. Gen. Appl. Microbiol. 43: 349-354.

Henry, L. M., M. C. Maiden, J. Ferrari, and H. C. Godfray. 2015. Insect life history and the evolution of bacterial mutualism. Ecol. Lett. 18: 516-525.

Jousselin, E., A. Cour d'Acier, F. Vanlerberghe-Masutti, and O. Duron. 2013. Evolution and diversity of Arsenophonus endosymbionts in aphids. Mol. Ecol. 22: 260-270.

Katoh, K., and D. M. Standley. 2013. MAFFT multiple sequence alignment software version 7: improvements in performance and usability. Mol. Biol. Evol. 30: 772-780.

Larkin, M. A., G. Blackshields, N. P. Brown, R. Chenna, P. A. McGettigan, H. McWilliam, F. Valentin, I. M. Wallace, A. Wilm, R. Lopez, et al. 2007. Clustal W and Clustal X version 2.0. Bioinformatics. 23: 2947-2948.

Latham, D. R., and N. J. Mills. 2010. Life history characteristics of Aphidius transcaspicus, a parasitoid of mealy aphids (Hyalopterus species). Biol. Control 54: 147-152.

Latham, D. R., and N. J. Mills. 2012. Host instar preference and functional response of Aphidius transcaspicus, a parasitoid of mealy aphids (Hyalopterus species). BioControl. 57: 603-610.

Le Ralec, A., C. Anselme, Y. Outreman, M. Poirié, J. van Baaren, C. Le Lann, and J. J. van Alphen. 2010. Evolutionary ecology of the interactions between aphids and their parasitoids. C. R. Biol. 333: 554-565.

Leclant, F. 1996. Dossiers pucerons. dégâts et identification des pucerons. PHM Rev. Hortic. 369: 19-24.

Li, S., P. Falabella, S. Giannantonio, P. Fanti, D. Battaglia, M. C. Digilio, W. Völkl, J. J. Sloggett, W. Weisser, and F. Pennacchio. 2002. Pea aphid clonal resistance to the endophagous parasitoid Aphidius ervi. J. Insect Physiol. 48: 971-980

Lozier, J. D., G. K. Roderick, and N. J. Mills. 2007. Genetic evidence from mitochondrial, nuclear, and endosymbiont markers for the evolution of host plant associated species in the aphid genus Hyalopterus (Hemiptera: Aphididae). Evolution. 61: 1353-1367.

Lozier, J. D., R. G. Foottit, G. L. Miller, N. J. Mills, and G. K. Roderick. 2008a. Molecular and morphological evaluation of the aphid genus Hyalopterus Koch (Insecta: Hemiptera: Aphididae), with a description of a new species. Syst. Entomol. 1688: 1-19.

Lozier, J. D., G. K. Roderick, and N. J. Mills. 2008b. Evolutionarily significant units in natural enemies: Identifying regional populations of Aphidius transcaspicus (Hymenoptera: Braconidae) for use in biological control of mealy plum aphid. Biol. Control 46: 532-541.

Martinez, A. J., M. R. Doremus, L. J. Kraft, K. L. Kim, and K. M. Oliver. 2017. Multi-modal defenses in aphids offer redundant protection and increased costs likely impeding a protective mutualism. J. Anim. Ecol. 00: 1-14.

Martinez, A. J., K. L. Kim, J. P. Harmon, and K. M. Oliver. 2016. Specificity of multi-modal aphid defenses against two rival parasitoids. PLoS ONE 11: e0154670.

Martinez, A. J., S. G. Ritter, M. R. Doremus, J. A. Russell, and K. M. Oliver. 2014a. Aphid-encoded variability in susceptibility to a parasitoid. BMC Evol. Biol. 14: 127.

Martinez, A. J., S. R. Weldon, and K. M. Oliver. 2014b. Effects of parasitism on aphid nutritional and protective symbioses. Mol. Ecol. 23: 1594-1607.

McLean, A. H. C., and H. C. J. Godfray. 2015. Evidence for specificity in symbiont-conferred protection against parasitoids. Proc. R. Soc. Ser. B-Bio. 282: DOI:10.1098/rspb.2015.0977.

Montllor, C. B., A. Maxmen, and A. H. Purcell. 2002. Facultative bacterial endosymbionts benefit pea aphids Acyrthosiphon pisum under heat stress. Ecol. Entomol. 27: 189-195.

Moran, N. A., J. A. Russell, R. Koga, and T. Fukatsu. 2005a. Evolutionary relationships of three new species of Enterobacteriaceae living as symbionts of aphids and other insects. Appl. Environ. Microbiol. 71: 3302-3310.

Moran, N. A., P. H. Degnan, S. R. Santos, H. E. Dunbar, and H. Ochman. 2005 b. The players in a mutualistic symbiosis: insects, bacteria, viruses, and virulence genes. Proc. Natl. Acad. Sci. USA. 102: 16919-16926.

Munson, M. A., P. Baumann, and M. G. Kinsey. 1991. Buchnera gen. nov. and Buchnera aphidicola sp. nov., a taxon consisting of the mycetocyte-associated, primary endosymbionts of aphids. Int. J. Syst. Bacteriol. 41: 566-568.

Nováková, E., V. Hypsa, and N. A. Moran. 2009. Arsenophonus, an emerging clade of intracellular symbionts with a broad host distribution. BMC Microbiol. 9: 143.

Nyabuga, F. N., Y. Outreman, J. C. Simon, D. G. Heckel, and W. W. Weisser. 2010. Effects of pea aphid secondary endosymbionts on aphid resistance and development of the aphid parasitoid Aphidius ervi: a correlative study. Entomol. Exp. Appl. 136: 243-253.

Oliver, K. M., J. A. Russell, N. A. Moran, and M. S. Hunter. 2003. Facultative bacterial symbionts in aphids confer resistance to parasitic wasps. Proc. Natl. Acad. Sci. USA. 100: 1803-1807.

Oliver, K. M., N. A. Moran, and M. S. Hunter. 2005. Variation in resistance to parasitism in aphids is due to symbionts not host genotype. Proc. Natl. Acad. Sci. USA. 102: 12795-12800.

Oliver, K. M., N. A. Moran, and M. S. Hunter. 2006. Costs and benefits of a superinfection of facultative symbionts in aphids. Proc. Biol. Sci. 273 1273-1280.

Oliver, K. M., J. Campos, N. A. Moran, and M. S. Hunter. 2008. Population dynamics of defensive symbionts in aphids. Proc. R. Soc. Ser. B Biol. 275: 293-299.

Oliver, K. M., P. H. Degnan, M. S. Hunter, and N. A. Moran. 2009 Bacteriophages encode factors required for protection in a symbiotic mutualism. Science. 325: 992-994.

Oliver, K. M., P. H. Degnan, G. R. Burke, and N. A. Moran. 2010. Facultative symbionts in aphids and the horizontal transfer of ecologically important traits. Annu. Rev. Entomol. 55: 247-266.

Oliver, K. M., A. H. Smith, and J. A. Russell. 2014. Defensive symbiosis in the real world - advancing ecological studies of heritable, protective bacteria in aphids and beyond. Funct. Ecol. 28: 341-355.

Rakauskas, R., J. Havelka, and A. Zaremba. 2013. Mitochondrial COI and morphological specificity of the mealy aphids (Hyalopterus ssp.) collected from different hosts in Europe (Hemiptera, Aphididae). Zookeys 319: 255-267.

Rao, Q., S. Wang, Y. L. Su, X. L. Bing, S. S. Liu, and X. W. Wang. 2012. Draft genome sequence of "Candidatus Hamiltonella defensa," an endosymbiont of the whitefly Bemisia tabaci. J. Bacteriol. 194: 3558.

Rehman, A., and W. Powell. 2010. Host selection behaviour of aphid parasitoids (Aphidiidae: Hymenoptera). J. Plant Breed. Crop Sci. 2 : 299-311. 
Rouchet, R., and C. Vorburger. 2012. Strong specificity in the interaction between parasitoids and symbiont-protected hosts. J. Evol. Biol. 25: 2369-2375.

Ronquist, F., M. Teslenko, P. van der Mark, D. L. Ayres, A. Darling, S. Höhna, B. Larget, L. Liu, M. A. Suchard, and J. P. Huelsenbeck. 2012. MrBayes 3.2: efficient Bayesian phylogenetic inference and model choice across a large model space. Syst. Biol. 61: 539-542.

Rosen, D. 1986. The role of taxonomy in effective biological control programs. Agric. Ecosyst. Environ. 15: 121-129.

Russell, J. A., and N. A. Moran. 2006. Costs and benefits of symbiont infection in aphids: variation among symbionts and across temperatures. Proc. Biol. Sci. 273: 603-610.

Russell, J. A., A. Latorre, B. Sabater-Muñoz, A. Moya, and N. A. Moran. 2003 Side-stepping secondary symbionts: widespread horizontal transfer across and beyond the Aphidoidea. Mol. Ecol. 12: 1061-1075.

Sandström, J. P., J. A. Russell, J. P. White, and N. A. Moran. 2001. Independent origins and horizontal transfer of bacterial symbionts of aphids. Mol. Ecol. 10: 217-228.

Schmid, M., R. Sieber, Y. S. Zimmermann, and C. Vorburger. 2012 Development, specificity and sublethal effects of symbiont-conferred resistance to parasitoids in aphids. Funct. Ecol. 26: 207-215.

Staden, R., K. F. Beal, and J. K. Bonfield. 2000. The Staden package, 1998. Methods Mol. Biol. 132: 115-130.

Taylor, G. P., P. C. Coghlin, K. D. Floate, and S. J. Perlman. 2011. The host range of the male-killing symbiont Arsenophonus nasoniae in filth fly parasitioids. J. Invertebr. Pathol. 106: 371-379.

Tsuchida, T., R. Koga, H. Shibao, T. Matsumoto, and T. Fukatsu. 2002 Diversity and geographic distribution of secondary endosymbiotic bacteria in natural populations of the pea aphid, Acyrthosiphon pisum. Mol. Ecol. 11: 2123-2135.

Tsuchida, T., R. Koga, X. Y. Meng, T. Matsumoto, and T. Fukatsu. 2005. Characterization of a facultative endosymbiotic bacterium of the pea aphid Acyrthosiphon pisum. Microb. Ecol. 49: 126-133.

van der Wilk, F., A. M. Dullemans, M. Verbeek, and J. F. van den Heuvel. 1999. Isolation and characterization of APSE-1, a bacteriophage infecting the secondary endosymbiont of Acyrthosiphon pisum. Virology. 262: 104-113.

Vorburger, C. 2018. Symbiont-conferred resistance to parasitoids in aphids challenges for biological control. Biol. Control 116: 17-26.

Vorburger, C., C. Sandrock, A. Gouskov, L. E. Castañeda, and J. Ferrari. 2009. Genotypic variation and the role of defensive endosymbionts in an all-parthenogenetic host-parasitoid interaction. Evolution. 63: 1439-1450.

Vorburger, C., L. Gehrer, and P. Rodriguez. 2010. A strain of the bacterial symbiont Regiella insecticola protects aphids against parasitoids. Biol. Lett. 6: 109-111.

Vorburger, C., P. Ganesanandamoorthy, and M. Kwiatkowski. 2013. Comparing constitutive and induced costs of symbiont-conferred resistance to parasitoids in aphids. Ecol. Evol. 3: 706-713.

Wang, X.-G., and R. H. Messing. 2006. Potential host range of the newly introduced aphid parasitoid Aphidius transcaspicus (Hymenoptera: Braconidae) in Hawaii. Proc. Hawaiian Entomol. Soc. 38: 81-86.

Weldon, S. R., M. R. Strand, and K. M. Oliver. 2013. Phage loss and the breakdown of a defensive symbiosis in aphids. Proc. Biol. Sci. 280: 20122103.

Wulff, J. A., and J. A. White. 2015. The Endosymbiont arsenophonus provides a general benefit to soybean aphid (Hemiptera: Aphididae) regardless of host plant resistance (Rag). Environ. Entomol. 44: 574-581.

Zytynska, S. E., and W. W. Weisser. 2016. The natural occurrence of secondary bacterial symbionts in aphids. Ecol. Entomol. 41: 13-26. 